\title{
Pengaruh Edukasi Terhadap Pengetahuan Santri Mengenai Swamedikasi Obat Diare dengan Media Slide di Lembaga Tinggi Pesantren Luhur Kota Malang
}

\author{
Khairunnisa Yahya ${ }^{1}$, Ika Ratna Hidayati ${ }^{2 *}$, Sendi Lia Yunita $^{3}$

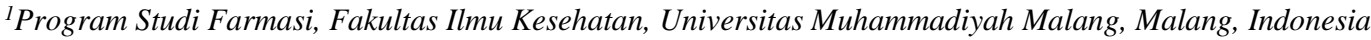

\begin{tabular}{l} 
INFO ARTIKEL \\
\hline Penerimaan \\
naskah: 04 \\
November 2021 \\
Penerimaan \\
naskah revisi: 18 \\
December 2021 \\
Disetujui untuk \\
dipublikasikan: 18 \\
December 2021
\end{tabular} \\ Kata kunci : \\ Swamedikasi, obat, \\ diare, media, slide

\section{A B S T R A K} \\ Pesantren merupakan lembaga pendidikan Islam yang pertama dan tertua di Indonesia dengan ciri khas \\ mempunyai pondok sebagai tempat tinggal para santri/santriwati. Dikarenakan cirri khusus pesantren yaitu \\ bermukim, maka penyakit menular seperti diare mudah dijumpai di pondok pesantren. Angka morbiditas dan \\ mortalitas dari penyakit diare masih terlampau tinggi di Indonesia, oleh karenanya sangat diperlukan edukasi \\ terkait swamedikasi obat diare. Dalam praktek swamedikasi diperlukan pengetahuan yang memadai agar \\ praktek swamedikasi yang dilakukan santri tepat dan dapat meminimalisir peluang terjadinya kesalahan dalam \\ praktek swamedikasi. Dijelaskan dalam penelitian lainnya bahwa edukasi dengan media elektronik berupa \\ slide PowerPoint lebih efektif dibandingkan dengan media cetak berupa leaflet, sehingga penelitian ini \\ menggunakan media slide Power Point agar lebih maksimal. Tujuan penelitian ini yaitu untuk mengetahui \\ pengaruh edukasi terkait swamedikasi obat diare terhadap pengetahuan santri dengan media slide \\ PowerPointdi Lembaga Tinggi Pesantren Luhur Kota Malang. Peneitian ini menggunakan penelitian pra- \\ eksperimental, dengan rancangan penelitian one group pretest posttest. Teknik pengambilan sampel dilakukan \\ secara non probability sampling dengan teknik purposive sampling. Instrument yang digunakan adalah \\ kuesioner yang telah valid dan reliabel, kemudian hasil tersebut dianalisis menggunakan analisis Uji \\ Wilcoxon dengan bantuan SPSS 25. Dalam penelitian ini diperoleh tingkat pengetahuan responden sebelum \\ diberikan edukasi bervariasi dengan persentase terbanyak memiliki tingkat pengetahuan kategori baik yaitu \\ $89,71 \%$, cukup sebanyak 7,35\% dan kurang baik sebanyak 2,94\%. Kemudian hasil tingkat pengetahuan \\ responden sesudah diberikan edukasi yaitu $100 \%$ baik. Berdasarkan perbandingan skor pretest dan posttest \\ yang diperoleh tingkat pengetahuan responden mengalami peningkatan setelah diberikan edukasi. Edukasi \\ mengenai swamedikasi obat diare menggunakan media slide PowerPoint berpengaruh terhadap tingkat \\ pengetahuan santri/santriwati Lembaga Tinggi Pesantren Luhur dengan nilai p 0,000.
}

\section{The Effect of Education on the Knowledge of the Santri Regarding the Self- Medicine of Diarrhea Drugs with Slide Media at the Luhur Islamic Boarding School, Malang}

Keywords:

Self-medication, medicine, diarrhea, media, slide

\section{$A B S T R A C T$}

Pesantren is the first and oldest Islamic educational institution in Indonesia with the characteristic of having a hut as a residence for students. Due to the special characteristics of pesantren, namely living, infectious diseases such as diarrhea are easy to find in Islamic boarding schools. Morbidity and mortality rates from diarrheal diseases are still too high in Indonesia, therefore education related to self-medication of diarrhea drugs is very much needed. In the practice of self-medication, adequate knowledge is needed so that the practice of self-medication carried out by students is appropriate and can minimize the chance of errors in the practice of self-medication. It was explained in another study that education using electronic media in the form of PowerPoint slides was more effective than print media in the form of leaflets, so this study used PowerPoint slides to make it more optimal. The purpose of this study was to identify the effect of education related to self-medication of diarrhea medicine on the knowledge of students with PowerPoint slides at the Luhur Islamic Boarding School Malang. This research used pre-experimental research, with a one group pretest posttest research design. The sampling technique was carried out by non-probability sampling with purposive sampling technique. The instrument used is a questionnaire that has been valid and reliable, then the results were analyzed using the Wilcoxon test analysis with the help of SPSS 25. In this study, the level of knowledge of respondents before being given education varied with the highest percentage having a good level of knowledge, namely $89.71 \%$, quite as much as $7.35 \%$ and less good as much as $2.94 \%$. Then the results of the level of knowledge of respondents after being given education are $100 \%$ good. Based on the comparison of pretest and posttest scores, the level of knowledge of respondents increased after being given education. Education about self-medication of diarrhea medicine using PowerPoint slide media affects the level of knowledge of students at the Luhur Islamic Boarding School with a p value of 0.000 . 


\section{Pendahuluan}

Swamedikasi atau pengobatan sendiri merupakan salah satu tindakan dalam mengobati penyakit yang dialami dengan cara pemilihan serta penggunaan obat oleh seseorang tanpa resep dokter. Kesalahan dalam praktek swamedikasi dapat terjadi karena tidak sesuainya pemilihan dan penggunaan obat (1). Kemenkes menyatakan dalam Riskesdas 2013, di Indonesia jumlah rumah tangga yang terdata mempunyai obat-obatan yang digunakan dalam tindakan swamedikasi sebanyak 35,2 (20). Kemudian terdapat $25,4 \%$ jumlah obat diare yang masih digunakan secara tidak rasional yang disimpan di rumah tangga. Sehingga sangat diperlukan pengetahuan yang memadai terkait swamedikasi di masyarakat (3).

Di Indonesia diare masih sering dijumpai dan juga dapat diobati sendiri. Penyakit diare masih menjadi penyakit endemis potensial Kejadian Luar Biasa (KLB) yang disertai dengan kematian. Selain itu Jawa Timur menempati urutan kedua dengan kasus diare terbanyak setelah Jawa Barat dengan total kasus sejumlah 1.071 .863 (4). Kemudian pada tahun2017, Case Fatality Rate (CFR) penyakit diare pada KLB di Indonesia 1,97\%, hal ini masih melampaui target yaitu $<1 \%$ (5). Selain itu, meninjau dari sarana kesehatan yang melayani diare, terjadi kenaikan kasus dari tahun 2017 sebanyak 60,4\% menjadi 61,7\% pada tahun 2019 (4,5). Oleh karena tingginya angka morbiditas dan mortalitas dari penyakit diare, maka sangat diperlukan edukasi sebagai bentuk pencegahan.

Pesantren merupakan lembaga pendidikan islam yang pertama dan tertua di Indonesia dengan ciri khas mempunyai pondok sebagai tempat tinggal para santri/santriwati dan juga terdapat kiai sebagai tempat untuk meminta fatwa dan nasihat serta sebagai sumber refrensi dan bertanya (6). Dikarenakan cirri khusus pesantren yaitu bermukim, maka penyakit menular masih sering dijumpai di pondok pesantren. Di pondok terkumpul santri/santriwati dengan perilaku, latar belakang social ekonomi dan kelompok usia yang berbeda-beda sehingga dapat dengan mudah ditemukan berbagai macam penyakit menular berpangkal pada lingkungan dan perilaku seperti diare, penyakit kulit, infeksi saluran pernapasan atas dan tuberculosis paru (7).

Dari penelitian sebelumnya diketahui bahwa pemberian edukasi lebih efektif bila menggunakan media elektronik berupa slide PowerPoint dibandingkan media cetak berupa leaflet, oleh karenanya dalam penelitian ini digunakan media slide PowerPoint agar pemberian edukasi dapat lebih maksimal (8). Dari hasil studi pendahuluan yang dilakukan di Lembaga Tinggi Pesantren Luhur Kota Malang diperoleh informasi bahwa belum pernah diadakannya penyuluhan kesehatan dan tidak tersedianya Pos Kesehatan Pesantren (Poskestren) sehingga ketika merasa sakit santri yang ada di pesantren tersebut hanya beristirahat dan mengkonsumsi obat dari kotak obat di kantor pengurus pesantren. Obat-obatan di kotak obat tersebut tidak selalu lengkap, mengakibatkan santri/santriwati membeli sendiri obat yang dibutuhkan di warung dan di Apotek terdekat. Penyakit yang umumnya dikeluhkan santri diantaranya batuk, demam, flu, dan diare. Oleh karenanya sangat diperlukan edukasi terkait swamedikasi obat diare agar praktek swamedikasi yang dilakukan santri tepat dan dapat meminimalisir peluang terjadinya kesalahan dalam praktek swamedikasi. Penelitian ini penting dilakukan untuk menilai apakah pemberian edukasi dapat mempengaruhi pengetahuan santri mengenai swamedikasi obat diare di Lembaga Tinggi Pondok Pesantren Luhur Kota Malang dengan media slide PowerPoint.

\section{Metode}

Penelitian ini merupakan penelitian pra-eksperimental dengan rancangan penelitian one group pretest posttest yang dilakukan di Lembaga Tinggi Pesantren Luhur Kota Malang pada tanggal 17 Juni 2021 dengan populasi sebanyak 211 responden. Responden merupakan santri/santriwati Pesantren Luhur Kota Malang. Teknik sampling yang digunakan adalah non probability sampling dengan teknik purposive sampling yang didasarkan pada criteria inklusi dan eksklusi. Kriteria inklusi dalam penelitian ini adalah mahasiswa Lembaga Tinggi Pesantren Luhur kota Malang yang memiliki umur minimal 17 tahun dan mahasiswa Lembaga Tinggi Pesantren Luhur kota Malang yang bersedia mengikuti penelitian. Sedangkan criteria ekslusi dalam penelitian ini adalah mahasiswa Pesantren Luhur kota Malang yang sedang mengambil kuliah jurusan kesehatan dan mahasiswa yang tidak mengisi kuesioner dengan lengkap. Dalam penentuan jumlah sampel digunakan rumus slovin yang dapat menghasilkan jumlah sampel yang sedikit pada sampel yang sangat besar tetapi bisa mewakili seluruh pupolasi dan kemudian diperoleh 68 responden dengan perhitungan sebagai berikut (9):

$$
\begin{aligned}
& n=\frac{N}{1+N(d)^{2}} \\
& n=\frac{211}{1+211(0,1)^{2}}=67,84
\end{aligned}
$$

Keterangan :

$\mathrm{n}=$ jumlah sampel

$\mathrm{N}=$ jumlah populasi

$\mathrm{d}=$ batas toleransi kesalahan(error tolerance)

Instrument yang digunakan adalah kuesioner yang sebelumnya telah dicobakan kepada 30 responden diluar sampel penelitian yang mirip dengan kriteria inklusi dan eksklusi yaitu di pondok pesantren yang berbeda, di pesantren Sabilurrosyad Kota Malang untuk menjaga kerahasiaan instrument sehingga dapat menghindari data bias. Uji Validitas dan Reabilitas dilakukan dengan menggunakan program SPSS 25 dengan melihat nilai signifikansinya. Dari uji validitas diperoleh 9 item pertanyaan dari 12 yang memiliki $r$ hitung lebih besar dari $r$ tabel 0,361 sehingga dinyatakan valid kemudian 3 item yang tidak valid dihapus karena terdapat item pertanyaan lain yang dapat mewakili pertanyaan tersebut dan terdapat dalam indikator yang sama. Selanjutnya 9 item tersebut 
dilakukan uji reliabilitas dan diperoleh hasil 0,703. Dari hasil tersebut maka kuisioner dinyatakan valid dan reliabel. Kuesioner ini memuat indicator berupa mengetahui definisi diare, penyebab diare, pencegahan diare, terapi yang tepat saat diare baik farmakologis dan non farmakologis dan penggunaan obat diare. Item pertanyaan dalam kuesioner mengacu pada kuesioner sebelumnya yaitu penelitian yang dilakukan oleh Wahyu adi untuk mengukur tingkat pengetahuan pasien terkait swamedikasi obat diare di beberapa apotek Kecamatan Dau Kabupaten Malang (10). Responden mengisi pretest sebelum diedukasi dan posttest sesudah pemberian edukasi. Kemudian skor dari pretest dan posttest tersebut dianalisis menggunakan analisis Uji Wilcoxon dengan menggunakan SPSS versi 25. Penelitian ini telah mendapatkan ijin etik penelitian dari Komisi Etik Penelitian Kesehatan Universitas Muhammadiyah Malang dengan nomor E,5.a/119/KEPK-UMM/VI/2021.

\section{Hasil dan Diskusi}

Hasil dari pretetst dan posttest dari 68 responden dalam penelitian ini diperoleh data karakteristik demografi dapat dilihat pada Tabel 1.

Tabel 1. Karakteristik Demografi Responden

\begin{tabular}{|c|c|c|}
\hline $\begin{array}{c}\text { Karakteristik } \\
\text { Responden }\end{array}$ & $\begin{array}{c}\text { Jumlah } \\
\text { Responden }\end{array}$ & Persentase \% \\
\hline \multicolumn{3}{|l|}{ Usia (tahun) } \\
\hline 17 & 1 & 1,47 \\
\hline 18 & 5 & 7,35 \\
\hline 19 & 22 & 32,35 \\
\hline 20 & 20 & 29,41 \\
\hline 21 & 16 & 23,53 \\
\hline 22 & 3 & 4,41 \\
\hline 23 & 1 & 1,47 \\
\hline \multicolumn{3}{|l|}{ Jenis Kelamin } \\
\hline Perempuan & 46 & 67,65 \\
\hline Laki-laki & 22 & 32,35 \\
\hline \multicolumn{3}{|l|}{ Jurusan } \\
\hline $\begin{array}{ll}\text { Sains } & \text { dan } \\
\text { Teknologi } & \end{array}$ & 36 & 52,94 \\
\hline $\begin{array}{ll}\text { Sosial dan } & \text { dal } \\
\text { Humaniora } & \end{array}$ & 32 & 47,06 \\
\hline \multicolumn{3}{|l|}{ Asal } \\
\hline Jawa Timur & 53 & 77,94 \\
\hline Jawa Tengah & 6 & 8,82 \\
\hline Jawa Barat & 4 & 5,88 \\
\hline $\begin{array}{l}\text { Kalimantan } \\
\text { Tengah }\end{array}$ & 1 & 1,47 \\
\hline Kalimantan Timur & 1 & 1,47 \\
\hline Kepulauan Riau & 1 & 1,47 \\
\hline $\begin{array}{ll}\text { Nusa } & \text { Tenggara } \\
\text { Barat } & \\
\end{array}$ & 1 & 1,47 \\
\hline Sulawesi Selatan & 1 & 1,47 \\
\hline
\end{tabular}

Pada Tabel 1 diatas, dapat dijelaskan bahwa, responden pada penelitian ini berusia 17-23 tahun dengan mayoritas berusia 19 tahun sebanyak 32,35\%. Sesuai dengan criteria inklusi dari penelitian yaitu mahasiswa yang memiliki umur minimal 17 tahun yang mana sudah dapat memahami literasi media (9). Dari data santri yang diperoleh dari pengurus pesantren Luhur, rentang usia santri 16-40 tahun. Umur memengaruhi pengetahuan seseorang karena meningkatnya umur berbanding lurus dengan kemampuan berpikir seseorang $(11,12)$. Responden berasal dari tempat yang berbeda-beda, mayoritas berasal dari Jawa Timur sebanyak 77,94\% dan sisanya berasal dari Kalimantan, Sulawesi hingga Nusa Tenggara Barat. Hal ini sesuai dengan hasil wawancara dengan pengurus pesantren bahwa sebagian besar santri berasal dari Jawa Timur. Semua responden berpendidikan tinggi dengan jurusan terbanyak yang mengisi kuesioner yaitu saintek (sains dan teknologi) sebanyak 52,94\%. Dari data santri yang diperoleh mayoritas jurusan responden pada bidang soshum (sosial dan humaniora). Pendidikan berpengaruh pada peningkatan kualitas diri manusia sehingga berkaitan erat dengan proses dalam mengambil sebuah keputusan, oleh karenanya dapat dikatakan bahwa tingkat pendidikan berpengaruh terhadap keputusan seseorang dalam praktik swamedikasi (13). Mayoritas responden ialah perempuan sebanyak 67,65\%. Jenis kelamin berkaitan dengan tindakan swamedikasi. Jenis kelamin terbanyak yang melakukan tindakan pengobatan sendiri adalah perempuan, dikarenakan perempuan memiliki kecenderungan untuk berhati-hati dalam tindakan swamedikasi dan lebih memutuskan untuk pergi kedokter terlebih dahulu dalam rangka berkonsultasi mengenai obat yang akan digunakan dibandingkan laki-laki (14).

Dari Tabel 2 diperoleh informasi bahwa semua responden pernah mengalami diare, dengan frekuensi diare terbanyak yang dialami responden ialah jarang sebanyak 57,35 . Hal ini sesuai dengan penelitian sebelumnya bahwa mayoritas mahasiswa mempunyai tingkat pengetahuan yang tinggi dan mempunyai perilaku gaya hidup yang sehat sehingga diperoleh kejadian tidak diare sebanyak 73,4\% (15). Diketahui sebanyak $79,41 \%$ responden pernah mengonsumsi obat diare. Kemudian dalam menangani diare sebanyak $61,76 \%$ responden membeli obat diare, $23,53 \%$ responden menjawab untuk dibiarkan saja, hal ini bisa dikarenakan diare dapat sembuh sendiri dan sisanya memilih pergi kedokter dan lainnya (minum herbal, larutan gula dan makan buah dan sayur). Hampir semua orang pernah mengalami diare, tetapi pada umumnya hanya berlangsung beberapa hari dan dapat sembuh sendiri (14). Mengenai informasi terkait penggunaan obat diare sebanyak $61,76 \%$ responden memperoleh informasi dari tenaga kesehatan.

Tingkat pengetahuan responden sebelum diberikan edukasi bervariasi dengan persentase terbanyak memiliki tingkat pengetahuan kategori baik yaitu $89,71 \%$, cukup sejumlah 7,35\% dan kurang baik sebanyak 2,94\%. Sebagian besar responden telah mempunyai pengetahuan yang baik tentang swamedikasi obat diare. Hasil ini didukung karena sebelumnya responden telah mendapatkan informasi mengenai penggunaan obat diare sehingga responden telah mempunyai pengetahuan yang cukup akan hal tersebut. Hasil ini sesuai dengan penelitian sebelumnya bahwa tingkat pengetahuan mahasiswa tentang tindakan 
swamedikasi diare $87,5 \%$ baik (16). Pengetahuan merupakan hal yang berperan penting dalam perilaku seseorang (17).

Tabel 2. Pertanyaan Pendahuluan

\begin{tabular}{|c|c|c|c|}
\hline \multicolumn{2}{|l|}{ Variabel } & Jumlah Responden & $\begin{array}{l}\text { Persentase } \\
\quad(\%)\end{array}$ \\
\hline \multicolumn{4}{|c|}{ Riwayat Diare } \\
\hline \multicolumn{2}{|c|}{ Pernah } & 68 & 100 \\
\hline \multicolumn{2}{|c|}{ Tidak Pernah } & 0 & 0 \\
\hline \multicolumn{4}{|c|}{ Frekuensi Terjadinya Diare } \\
\hline \multicolumn{2}{|c|}{ Jarang } & 39 & 57,35 \\
\hline \multicolumn{2}{|c|}{ Kadang-kadang } & 24 & 35,29 \\
\hline \multicolumn{2}{|c|}{ Sering } & 5 & 7,35 \\
\hline \multicolumn{4}{|c|}{ Menangani Diare } \\
\hline \multicolumn{2}{|c|}{ Membeli obat diare } & 43 & 63,24 \\
\hline \multicolumn{2}{|c|}{ Periksa kedokter } & 4 & 5,88 \\
\hline \multirow[t]{4}{*}{ Lainnya } & Dibiarkan saja & 16 & 23,53 \\
\hline & Minum Herbal & 3 & 4,41 \\
\hline & Minum Larutan Gula & 1 & 1,47 \\
\hline & $\begin{array}{l}\text { Makan buah dan } \\
\text { sayur }\end{array}$ & 1 & 1,47 \\
\hline \multicolumn{4}{|c|}{$\begin{array}{l}\text { Riwayat Mengonsumsi Obat } \\
\text { Diare }\end{array}$} \\
\hline \multicolumn{2}{|c|}{ Pernah } & 54 & 79,41 \\
\hline \multicolumn{2}{|c|}{ Tidak Pernah } & 14 & 20,59 \\
\hline \multicolumn{4}{|c|}{$\begin{array}{l}\text { Informasi Penggunaan Obat } \\
\text { Diare }\end{array}$} \\
\hline \multicolumn{2}{|c|}{ Tenaga Kesehatan } & 42 & 61,76 \\
\hline \multicolumn{2}{|c|}{ Non Tenaga Kesehatan } & 26 & 38,24 \\
\hline
\end{tabular}

Setelah menerima edukasi, responden diberikan posttest. Hasil menunjukkan tingkat pengetahuan responden sesudah diberikan edukasi yaitu $100 \%$ baik. Hal ini dikarenakan responden telah menerima informasi yang memadai terkait swamedikasi obat diare yang diberikan oleh peneliti. Perihal ini sesuai dengan teori bahwa faktor yang mempengaruhi pengetahuan diantaranya penerimaan informasi (18). Dalam pengetahuan dibutuhkan informasi juga dihasilkan informasi. Dari informasi yang diperoleh tersebut dapat meningkatkan pengetahuan seseorang yang akan menyebabkan seseorang tersebut sadar dan akan berperilaku lebih baik (19). Dalam praktek swamedikasi apoteker dapat mendampingi pasien dalam memberikan saran terkait pemilihan dan penggunaan obat untuk menambah pengetahuan dari pasien tersebut.

Tabel 1. Perbandingan tingkat pengetahuan responden sebelum dan sesudah diberikan edukasi

\begin{tabular}{lccccc}
\hline Kategori & Indikato & \multicolumn{2}{c}{ Pretest } & \multicolumn{2}{c}{ Posttest } \\
\cline { 3 - 6 } $\begin{array}{c}\text { Tingkat } \\
\text { Pengetah } \\
\text { uan }\end{array}$ & r $(\%)$ & $\begin{array}{c}\text { Jumla } \\
\text { hRes } \\
\text { pond } \\
\text { en }\end{array}$ & $\begin{array}{c}\text { Persenta } \\
\text { se }(\%)\end{array}$ & $\begin{array}{c}\text { Jumla } \\
\text { hRes } \\
\text { pond } \\
\text { en }\end{array}$ & $\begin{array}{c}\text { Persentas } \\
\text { e }(\%)\end{array}$ \\
\hline Baik & $76-100$ & 61 & 89,71 & 68 & 100 \\
\hline Cukup & $56-75$ & 5 & 7,35 & 0 & 0 \\
\hline $\begin{array}{l}\text { Kurang } \\
\text { Baik }\end{array}$ & $\leq 55$ & 2 & 2,94 & 0 & 0 \\
\hline Jumlah & & $\mathbf{6 8}$ & $\mathbf{1 0 0}$ & $\mathbf{6 8}$ & $\mathbf{1 0 0}$ \\
\hline
\end{tabular}

Tabel 2. Analisis Uji Wilcoxon

\begin{tabular}{lr}
\hline \multicolumn{3}{c}{ Test Statistics $^{\mathrm{a}}$} \\
\hline & $\begin{array}{r}\text { SK TOTAL_POST - } \\
\text { SK TOTAL_PRE }\end{array}$ \\
\hline $\mathrm{Z}$ & $-6.049^{\mathrm{b}}$ \\
\hline Asymp. Sig. (2-tailed) & .000 \\
\hline a. Wilcoxon Signed Ranks Test & \\
\hline b. Based on negative ranks. & \\
\hline
\end{tabular}

Dari analisis Uji Wilcoxon diperoleh nilai probabilitas (Asymp. Sig.) 0,000 yang menunjukkan edukasi berpengaruh pada pengetahuan santri. Hasil penelitian ini berbanding lurus dengan penelitian pada masyarakat di Kelurahan Sambiroto dan Kelurahan Kedungmundu, Kota Semarang bahwa penyuluhan dengan media Powerpoint berhasil meningkatkan pengetahuan masyarakat tentang leptospirosis (20). Selain itu dalam penelitian yang dilakukan pada masyarakat di kelurahan Mamburungan Timur juga menunjukkan adanya pengaruh pemberian edukasi kesehatan dengan menggunakan Slide Powerpoint terhadap pengetahuan mengenai kesehatan di masa lanjut usia (21). Edukasi yang diberikan pada masyarakat di Dusun Ulusadar, Kabupaten Seram bagian Barat juga berpengaruh terhadap pengetahuan dan upaya pencegahan stunting (22). Selain terdapat penelitian yang sejalan dengan hasil yang diperoleh, terdapat juga hasil penelitian yang berbanding terbalik yang dilakukan pada masyarakat Desa Kutasari Baturaden Purwokerto yaitu pemberian edukasi tidak menunjukkan perubahan yang signifikan terhadap pengetahuan sebelum dan sesudah diedukasi tentang informasi obat yang perlu diketahui oleh masyarakat (23). Hal ini dapat disebabkan karena mayoritas responden belum berpendidikan tinggi sehingga penerimaan informasi dalam hal ini edukasi kurang baik. Tingkat Pendidikan mempengaruhi penerimaan informasi, informasi akan semakin mudah diterima bila tingkat pendidikannya semakin tinggi yang menyebabkan terjadi peningkatan pengetahuan dan kualitas hidup (13). Peneliti menyadari dalam suatu penelitian pasti terdapat kekurangan. Limitasi dalam penelitian terletak dalam proses penelitian ketika pemberian edukasi. Peneliti menyadari pemahaman responden saat diberikan edukasi dapat dipengaruhi oleh cara peneliti dalam menyampaikan materi, untuk menyelesaikan masalah ini peneliti membuka sesi pertanyaan untuk responden yang belum memahami materi tersebut dan membahas kembali materi yang belum dipahami. Pada penelitian ini dapat disimpulkan bahwa edukasi mengenai swamedikasi obat diare menggunakan media slide PowerPoint berpengaruh terhadap tingkat pengetahuan santri/santriwati Lembaga Tinggi Pesantren Luhur kota Malang. 


\section{Daftar Pustaka}

1. Rikomah SE. Farmasi Klinik. Edisi 1, C. Yogyakarta: Deepublish; 2019.

2. Kemenkes RI. Riset Kesehatan Dasar 2013 [Internet]. Badan Penelitian dan Pengembangan Kesehatan Kementrian Kesehatan RI; 2013 [cited 2020 Feb 11]. Available from: https://www.litbang.kemkes.go.id/laporan-riset-kesehatandasar-riskesdas/

3. Raini M, Gitawati R, Rooslamiati I. Kerasionalan Penggunaan Obat Diare yang Disimpan di Rumah Tangga di Indonesia. J Kefarmasian Indones. 2015;5(1):49-56.

4. Kemenkes RI. Profil Kesehatan Indonesia Tahun 2019 [Internet]. Kementrian Kesehatan Republik Indonesia. Kementerian Kesehatan Republik Indonesia; 2020 [cited 2021 Jan 11]. p. 164. Available from: https://www.kemkes.go.id/folder/view/01/structure-publikasipusdatin-profil-kesehatan.html

5. Kemenkes RI. Riskesdas 2018. Development. 2018;1-220.

6. DM H. Sejarah Pesantren di Indonesia. Al-Ta'dib J Kaji Ilmu Pendidik [Internet]. 2013;6(2):145-58. Available from: https://ejournal.iainkendari.ac.id/index.php/al-

tadib/article/view/311/301

7. Zakiudin A, Shaluhiyah Z. Perilaku Kebersihan Diri (Personal Hygiene) Santri di Pondok Pesantren Wilayah Kabupaten Brebes. J Promosi Kesehat Indones. 2016;11(2):64-83.

8. Bd F, Susanti D, Hidayah R. Perbedaan Efektivitas Promosi Kesehatan Dengan Media Leaflet Dan Slide Terhadap Tingkat Pengetahuan Dan Sikap Ibu Tentang Imunisasi Measles Rubella Di Posyandu Bahari Iv Dan V Lubuk Buaya Kota Padang Tahun 2019. J Kesehat Mercusuar. 2019;2(1):1-5.

9. Riyanto S, Hatmawan AA. Metode Riset Penelitian Kuantitatif Penelitian di Bidang Manajemen, Teknik, Pendidikan Eksperimen [Internet]. Yogyakarta: Deepublish; 2020. 12-15 p. Available from: https://books.google.co.id/books?id=W2vXDwAAQBAJ\&pg $=$ PA12\&dq=rumus+slovin $\&$ hl $=$ en $\&$ sa $=X \& v e d=2$ ahUKEwjpdTRotvtAhXYbn0KHWcbBcoQ6AEwAXoECAUQAg\#v=o nepage $\& \mathrm{q}=$ rumus lemes $\& \mathrm{f}=$ false

10. Wahyuadi MS. Hubungan Tingkat Pengetahuan dan Perilaku Swamedikasi Obat Diare. Universitas Muhammadiyah Malang; 2018.

11. Muttaqin MZ. Kemampuan literasi media. 2016;5(2):13-4. 12. Simamora RH. Pengaruh Penyuluhan Identifikasi Pasien dengan Menggunakan Media Audiovisual Terhadap Pengetahuan Pasien Rawat Inap. J Keperawatan Silampari. 2019;3(1):342-51.

13. Aeni N, Yuhandini DS. Pengaruh Pendidikan Kesehatan Dengan Media Video Dan Metode Demonstrasi Terhadap Pengetahuan SADARI. Care J Ilm Ilmu Kesehat. 2018;6(2):162-74.

14. Robiyanto R, Rosmimi M, Untari EK. Analisis Pengaruh Tingkat Pengetahuan Masyarakat Terhadap Tindakan Swamedikasi Diare Akut Di Kecamatan Pontianak Timur. Edukasi J Pendidik. 2018;16(1):143-4.

15. Trikora E, Siwiendrayanti A. Hubungan Praktik Cuci Tangan, Kriteria Pemilihan Warung Makan Langganan dan Sanitasi Warung dengan Kejadian Diare pada Mahasiswa
Universitas Negeri Semarang. Unnes $J$ Public Heal. 2015;4(1):39-48.

16. Kurniasih KA, Supriani S, Yuliastuti D. Analisis Faktor Tingkat Pengetahuan Masyarakat Tentang Tindakan Swamedikasi Diare. Media Inf. 2020;15(2):101-5.

17. Sari NF, Hidayati IR, Atmadani RN. Hubungan Pengetahuan tentang Penggunaan OAD pada Pasien Diabetes Mellitus Tipe 2 terhadap Kepatuhan Penggunaan Obat Antidiabetes Oral di Puskesmas Singosari Malang.Jurnal Kesehatan Islam. 2021;10.

18. Wawan A, Dewi M. Teori \& Pengukuran Pengukuran Sikap dan Perilaku Manusia. Yogyakarta: Nuha Medika; 2011. 19. Khasanah U, Sari GK. Hubungan tingkat pengetahuan ibu tentang diare dengan perilaku pencegahan diare pada balita. $J$ Kesehat Samodra Ilmu. 2016;7(2):149-60.

20. Wijayanti T, Isnani T, Kesuma AP. Pengaruh Penyuluhan (Ceramah dengan Power Point) terhadap Pengetahuan tentang Leptospirosis di Kecamatan Tembalang, Kota Semarang Jawa Tengah. Balaba J Litbang Pengendali Penyakit Bersumber Binatang Banjarnegara. 2016;12(1):39-46.

21. Haris, Aris M, M M. Peningkatan Pengetahuan Lanjut Usia melalui Pendidikan Kesehatan dengan Menggunakan Media Power Point. Media Karya Kesehat. 2019;2(2):164-77.

22. Waliulu SH. Pengaruh Edukasi Terhadap Tingkat Pengetahuan Dan Upaya Pencegahan Stunting Anak Usia Balita. J Penelit Kesehat Suara Forikes. 2018;9(4):269-72.

23. Pratiwi H, Nuryanti N, Fera VV, Warsinah W, Sholihat NK. Pengaruh Edukasi Terhadap Pengetahuan, Sikap, Dan Kemampuan Berkomunikasi Atas Informasi Obat. Kartika $J$ Ilm Farm. 2016;4(1):10-5. 